\title{
The laboratory in the multidisciplinary diagnosis of differences or disorders of sex development (DSD)
}

\author{
I) Physiology, classification, approach, and methodology \\ II) Biochemical and genetic markers in 46,XX DSD
}

https://doi.org/10.1515/almed-2021-0042

Received December 14, 2020; accepted February 24, 2021;

published online July 8,2021

\section{Abstract}

Objectives: The development of female or male sex characteristics occurs during fetal life, when the genetic, gonadal, and internal and external genital sex is determined (female or male). Any discordance among sex determination and differentiation stages results in differences/disorders of sex development (DSD), which are classified based on the sex chromosomes found on the karyotype.

Content: This chapter addresses the physiological mechanisms that determine the development of female or male sex characteristics during fetal life, provides a general classification of DSD, and offers guidance for clinical, biochemical, and genetic diagnosis, which must be established by a multidisciplinary team. Biochemical studies should include general biochemistry, steroid and peptide hormone testing either at baseline or by stimulation testing. The genetic study should start with the determination of the karyotype, followed by a molecular study of the 46,XX or 46,XY karyotypes for the identification of candidate genes.

Summary: 46,XX DSD include an abnormal gonadal development (dysgenesis, ovotestes, or testes), an androgen excess (the most frequent) of fetal, fetoplacental, or maternal origin and an abnormal development of the

*Corresponding author: Dr. María Luisa Granada, MD, PhD, Department of Clinical Biochemistry, Hospital Germans Trias i Pujol, Autonomous University of Barcelona, Crta. Canyet s/n, 08916, Badalona, Spain, E-mail: granadaybern@gmail.com. https:// orcid.org/0000-0002-6816-7566

Laura Audí, Growth and Development Research Group, Vall d'Hebron Research Institute (VHIR), Center for Biomedical Research on Rare Diseases (CIBERER), Instituto de Salud Carlos III, Barcelona, Catalonia, Spain internal genitalia. Biochemical and genetic markers are specific for each group.

Outlook: Diagnosis of DSD requires the involvement of a multidisciplinary team coordinated by a clinician, including a service of biochemistry, clinical, and molecular genetic testing, radiology and imaging, and a service of pathological anatomy.

Keywords: 46,XX DSD; biochemical diagnosis; differences/disorders of sex development (DSD); genetic diagnosis.

\section{Physiology, classification, approach, and methodology}

\section{1) Physiology of sex differentiation and variant classification}

Female and male sex characteristics are determined during fetal life by complex biological processes involving cascades of gene expression, which proteins have highly specific functions in location and time [1-3]. Genetic sex is established at conception, when a spermatozoon (with $\mathrm{X}$ or Y sex chromosome) fertilizes an oocyte (X chromosome), which results in a diploid $46, \mathrm{XX}$ or $46, \mathrm{XY}$ cell that determines the genetic sex. During the first weeks of embryonic life, sexually indifferent gonads and genitalia develop. The development of the urogenital sinus and the adreno-gonadal ridge occurs by the fourth week. The development of the bipotential gonad requires a cascade of gene expression (well characterized in humans: EMX2, CBX2, NR5A1, GATA4, and WT1) [1, 3].

From the sixth week, the presence of a Y chromosome and its $S R Y$ gene activates a cascade of genes that mediates the development of the undifferentiated gonad into a testis [4] and inhibits the expression of genes that induce gonad 
development into an ovary $[1,3,5,6]$. Gonadal development is mediated by complex interactions between antagonic genes regulating processes that determine differentiation into a testis or an ovary [7] (Figure 1).

When gonads are sexually indifferent, male and female embryos share two genital ducts (Mullerian and Wolffian ducts) and external genitalia (genital tubercle and labioscrotal folds) [8]. Differentiation into internal and external genitalia depends on the secretion of specific hormones by the testes to an adequate amount following a specific timeline. Internal male genitalia require the secretion and action of testosterone ( $\mathrm{T}$ ), which causes Wolffian ducts to develop into the epididymis and vas deferens. The antiMullerian hormone (AMH) is also involved in this process, induces Mullerian duct regression and its activity is mediated by its receptor (AMHR2) [8]. The development of the prostate and external genitalia requires T metabolism, which is converted into dihydrotestosterone (DHT) by 5alpha-reductase type 2 [9] (Figure 1).
In the absence of AMH and elevated androgen concentrations ( $\mathrm{T}$ and DHT), internal and external female genitalia develop (Figure 1). Although the murine model of estrogen receptor (ER) knockout suggests that estrogens could feminize the genital tubercle by mediation of ER [10], the morphology of the external genitalia of a female newborn with complete resistance to estradiol (E2) has not yet been described.

Any alteration along developmental stages may disrupt normal sex development, resulting in disorders/ differences of sex development (DSD) [11], congenital conditions where the chromosomal, gonadal and/or genital development is atypical or different to the most frequent forms of development.

The Chicago Consensus [11] categorizes the causes of DSD according to the karyotype. Hence, DSD are categorized into three major groups: 1) Sex chromosome DSD, which occurs when the arrangement of sex chromosomes is different from the XX or XY pair; 2) 46,XX DSD with female

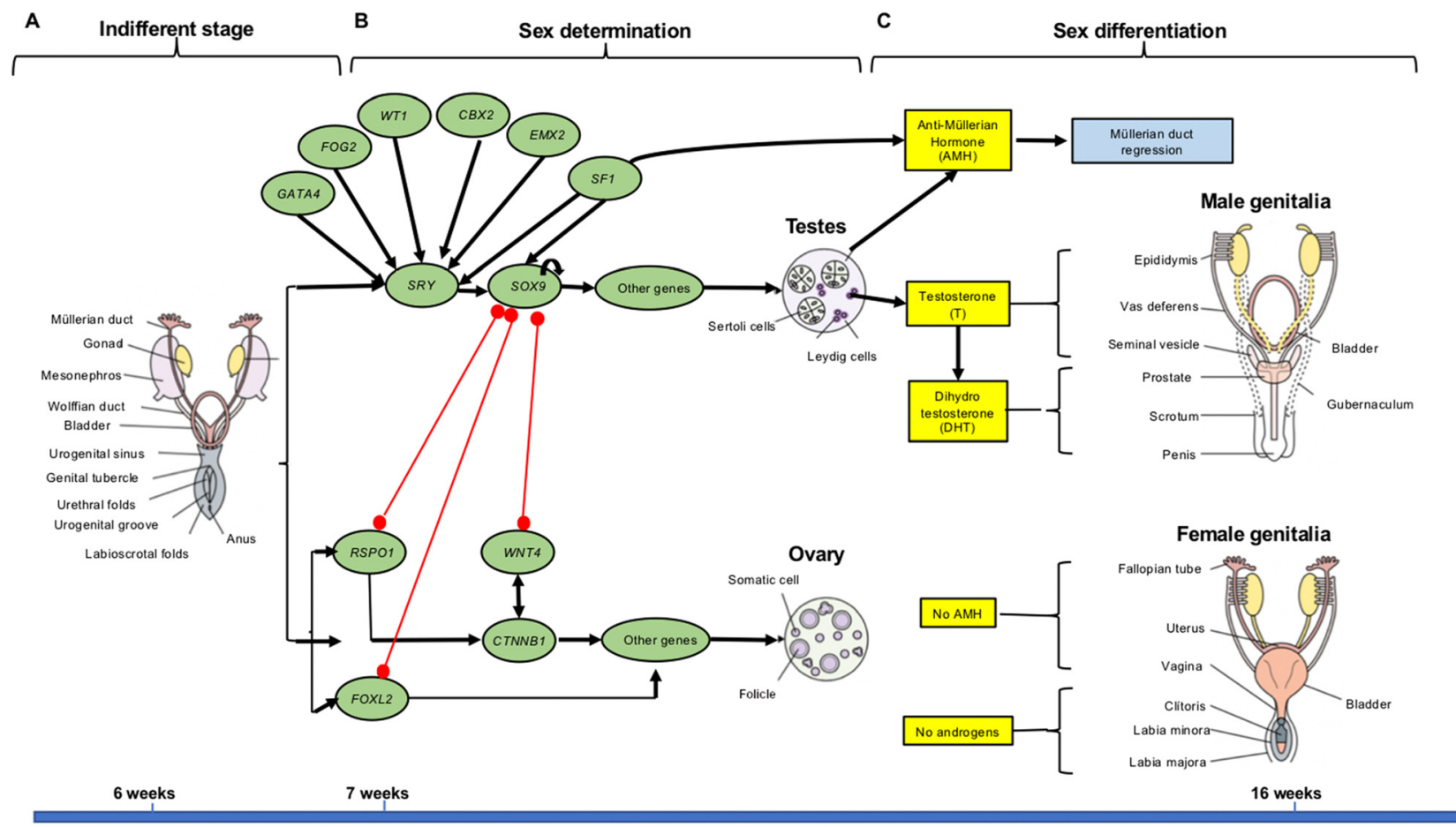

Weeks of gestation

Figure 1: Human sex development during fetal life.

(A) Indifferent stage: Bipotential gonads are developed by 5 weeks of life, as well as two pairs of genital ducts (Mullerian and Wolffian ducts), common external genitalia comprise the genital tubercle, the urethral folds, the urogenital groove and the labioscrotal folds. This stage ends by the sixth week. (B) Sex determination: Starts between sixth and seventh week when somatic cells and gonocytes in the bipotential gonad begin to differentiate into testicular or ovarian cells, depending on the presence and activation or repression of signaling pathways. Black arrows indicate gene activation whereas red ones indicate gene repression. (C) Sex differentiation: Internal and external genitalia differentiation depends on the presence or absence of testicular hormones (antiMullerian hormone [AMH] and testosterone [T] and dihydrotestosterone [DHT]) (with permission from ref. [16]). 
karyotype, and 3) 46,XY DSD with male karyotype (Table 1). Each group is divided into subgroups (Table 1). In Groups 2 and 3, a broad range of genes are involved, which increase over the years.

In Group 1, sex chromosome DSD is defined by the number or arrangement of sex chromosomes (Table 1). The most frequent are: 47,XXY (Klinefelter syndrome); 45,X0 (Turner syndrome) and its variants, including 45,X/46,XY mosaicism (or mixed gonadal dysgenesis); 46, $\mathrm{XX} / 46, \mathrm{XY}$ mosaicism (true sex chromosome chimerism or ovotesticular DSD); and 47,XYY.

Group 2, with 46,XX DSD karyotype (Table 1), includes: 1) Gonadal development disorders (CGD, PGD, ovotesticular chimerism [ovotesticular DSD], or testicular development [testicular DSD]); 2) genital development disorders caused by exposure to excess androgen levels (from fetal, fetoplacental or maternal origin) that cause the virilization of external genitalia; and 3) internal genitalia development disorders.

Group 3, with 46,XY karyotype (Table 1), includes: 1) Gonadal development disorders ([CGD, PGD, ovotesticular development [ovotesticular DSD], or ovarian development [ovarian DSD]); 2) disorders of androgen synthesis or action; 3) disorders of AMH synthesis or action; and 4) complex malformative syndromes affecting the development of the genitourinary and digestive system and severe early-onset intrauterine growth retardation, which is associated with hypospadias.

With the exception of Group 1, sex chromosome DSD (especially, Klinefelter syndrome with 47,XXY karyotype), and Group 3, 46,XY DSD male infants born with congenital hypospadias, the population frequency of Group 2 and 3 DSD is so low that they are considered "rare diseases" (population frequency $<1 / 2,000$ ).

\section{2) Multidisciplinary teams for DSD diagnosis}

DSD manifests either at birth or early after birth in the form of ambiguous external genitalia, by discordance between prenatal karyotype and genital development, a family history of DSD, concurrent acute adrenal insufficiency, or when the presence of a gonad is detected in an inguinal hernia. Later in life, during puberty, DSD is identified by discordances between gonadal and genital development. In addition, undiagnosed adults might seek medical advice for infertility or other health problems such as arterial hypertension. Studies to investigate the etiology of these problems may lead to the detection of a DSD.

Diagnosis of the cause of a DSD is challenging and will depend on the knowledge and skills of each specialist involved, added to the performance of the multidisciplinary team [11, 12]. All protocols emphasize that DSD diagnosis requires the involvement of a multidisciplinary team coordinated by a clinician $[12,13]$ that includes a Service of Biochemistry (general biochemistry and specific markers or hormones); a Service of Clinical and Molecular Genetics (initial karyotype and interpretation of the results of other studies will guide further studies); a Service of Radiology and Imaging (pelvic ultrasonography to detect internal genital structures and the presence of intraabdominal gonads); and a Service of Anatomic Pathology (when analysis of gonad structure is required).

A variety of diagnostic algorithms have been designed [13-16], which have evolved as new technologies emerged, mainly in the fields of imaging, biochemistry and, most importantly, molecular diagnostics [17-21].

\section{3) Biochemical and genetic studies for the diagnosis of DSD}

\section{a) Basal biochemical studies}

Biochemical tests and, especially, hormone determinations, play a crucial role in initial diagnosis of DSD, follow-up, and monitoring of response to treatment. There are two major groups of hormones: steroid and peptide hormones.

Steroid hormones (Figure 2) are synthetized from cholesterol in the adrenal cortex, the gonads, and the placenta, although they are metabolized in numerous peripheral tissues. The methods for steroid hormone determination in blood and urine have evolved over time to the current use of immunoassay and mass spectrometry. There are commercially available immunoassays for the steroids most frequently measured in routine practice. However, determination of other parameters of interest in the diagnosis of DSD such as corticosterone, deoxycorticosterone, 17-OH-pregnenolone, and DHT requires the use of liquid chromatography-mass spectrometry (LC-MS/MS) [22, 23]. International scientific societies recommend the use of mass spectrometry-based methods (LC-MS/MS and gas chromatography-mass spectrometry [GC-MS/MS]) for measuring sex steroids and their precursors in the diagnosis of DSD, especially, in neonates [24]. These methods measure different steroids in the same sample, including metabolites that cannot be determined by specific immunoassays [25]. Steroids can be measured in different samples: serum, blood, saliva, and urine [26]. It is very important that the laboratory meets quality standards, is involved in external quality assurance programs, and establishes specific age- and sex-specific reference 
Table 1: Classification of disorders or differences of sex development (DSD) based on the sex chromosomes present in the karyotype [11].

1) Sex chromosome DSD

1. $47, \mathrm{XXY}$ : Klinefelter syndrome and variants

2. $45, \mathrm{X} 0$ and $45, \mathrm{X0} / 46, \mathrm{XX}$ mosaicism (Turner syndrome and variants)

3. $45, \mathrm{X0} / 46, \mathrm{XY}$ mosaicism (mixed gonadal dysgenesis)

4. $46, \mathrm{XX} / 46, \mathrm{XY}$ mosaicism (ovotesticular DSD)

5. $47, \mathrm{XYY}$

2) $46, X X$ DSD

1. Abnormal gonadal development

a. Partial (PGD) or complete (CGD) gonadal dysgenesis

b. Ovotesticular DSD

c. Testicular DSD

2. Abnormal genital development for androgen excess

\section{Fetal production:}

a. 21 hydroxylase deficiency

b. $3 \beta$-hydroxy steroid deficiency

c. 11- $\beta$ hydroxylase deficiency

d. Glucocorticoid resistance

e. Estrogen resistance

Feto-placental production:

a. P450-oxidoreductase deficiency

b. Placental and fetal aromatase deficiency

c. Androgen secreting fetal or placental tumors

Material origin:

a. Therapeutic agents or environmental pollutants

b. Maternal CAH

c. Maternal virilizing tumors (luteomas, Krukenberg tumor)

3. Abnormal development of internal genitalia

a. Hand-foot-genital syndrome

b. MURCS syndrome (Mullerian aplasia, renal aplasia, cervico-thoracic eomite abnormalities)

c. MRKH syndrome (Mayer-Rokitansky-Kuster-Hauser), types I and II

3) $46, X Y$ DSD

1. Abnormal gonadal development

a. Partial (PGD) or complete (CGD) gonadal dysgenesis

b. Ovotesticular DSD

c. Ovarian DSD

2. Abnormal genital development secondary to deficient Disorders of androgen synthesis: androgen synthesis or action

a. Insensitivity to LH (Leydig cell aplasia/hypoplasia)

b. 7-dehydrocholesterol reductase deficiency (Smith-Lemli-Opitz syndrome)

c. Star protein deficiency (lipoid congenital adrenal hyperplasia)

d. Cholesterol desmolase deficiency

e. $3 \beta$-hydroxy steroid dehydrogenase type 2 deficiency

f. 17 $\alpha$-hydroxylase/17-20 desmolase deficiency

g. P450-oxidoreductase deficiency

h. Cytochrome $B 5$ deficiency

i. Defective backdoor pathway adrenal steroidogenesis

j. $17 \beta$-hydroxy steroid dehydrogenase type 3 deficiency

k. $5 \alpha$-reductase type 2 deficiency

l. Isolated hypospadias and/or cryptorchidism

Disorders of androgen action:

a. Complete or partial androgen insensitivity

b. Therapeutic agents or environmental pollutants

3. Abnormal genital development secondary to defective Persistent Müller ducts: anti-Müllerian (AMH) hormone synthesis or action

a. AntiMullerian hormone deficiency

b. Resistance to antiMullerian hormone

4. Complex malformation syndromes
a. Malformative syndromes with abnormal genital development (cloacal malformations, Aarskog syndrome, Robinow syndrome, among others)

b. Severe, early-onset, intrauterine growth restriction

DSD, disorder or different sex development; CAH, congenital adrenal hyperplasia. 
intervals [24]. Given that adrenal steroids have a marked circadian rhythm, it is recommended that determination is performed early in the morning (8-9 a.m.).

Peptide hormones are determined by noncompetitive immunoassays, which have a high sensitivity but which specificity is not always known. The lack of gold-standard methods and inconsistent standardization hinder interassay comparison. Thus, age- and sex-specific reference values are required for each assay [27, 28]. Peptide hormones related to sex development have a marked sexual dimorphism. In the first years of life of male infants, luteinizing hormone (LH) concentrations are higher than those of follicle-stimulating hormone (FSH), and the LH/FSH ratio is clearly higher [29]. AMH and inhibin B (INHB) concentrations are 100 times and 10 times higher, respectively, in males than in females. A guide was recently published for peptide hormone testing for the diagnosis of DSD [30].

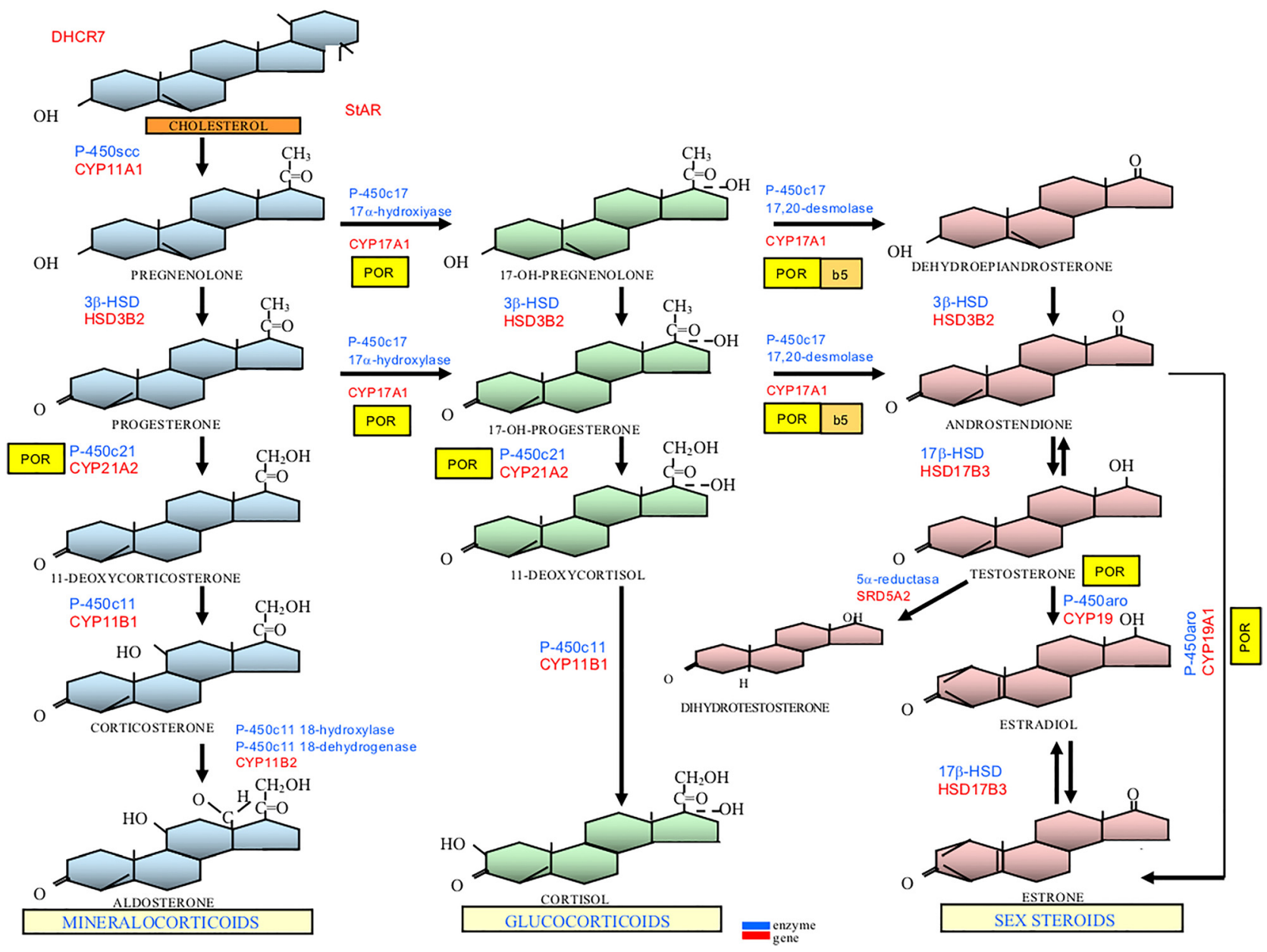

Figure 2: Adrenal and gonadal steroidogenesis.

In the adrenal glands, biosynthesis progresses from cholesterol to cortisol (glucocorticoid pathway) and to aldosterone (mineralocorticoid pathway). In the gonads, precursors progress to sex steroids: testosterone (T) as main androgen and estradiol as main estrogen. $T$ is peripherally metabolized into dihydrotestosterone (DHT) as the most active androgen. In blue: Enzyme abbreviations; in red: Enzyme coding gene abbreviations; yellow square: Coenzyme POR (P450-oxidoreductase); beige square: Cytochrome b5. DHCR7, DHCR7 gene (7alphadehydrocholesterol reductase); StAR, steroid acute regulatory protein (StAR gene); P-450scc, P-450 side-chain cleavage, cholesterol

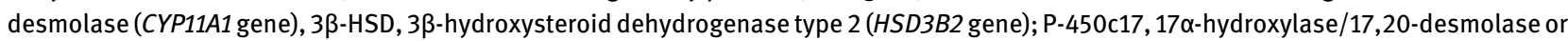
lyase (CYP17A1 gene); P-450c21, 21-hydroxylase (CYP21A2 gene); P-450c11, 11ß-hydroxylase type 1 (CYP11B1 gene); P-450c11 18-hydroxylase [corticosterone methyl-oxidase type 1 (CMO-I)] and P-450c11 18-dehydrogenase [corticosterone methyl-oxidase type II (CMO-II)] (CYP11B2 gene); $17 \beta$-HSD, $17 \beta$-hydroxysteroid dehydrogenase type 3 or 17 -ketoreductase (HSD17B3 gene), $5 \alpha$-reductase type 2 (SRD5A2 gene); and P-450aro, aromatase (CYP19A1 gene). 


\section{b) Functional tests}

In some cases, basal hormone testing is not informative enough and stimulation tests are required to identify secretion deficiencies.

There are three types of functional tests:

\section{b-1) Adrenocorticotropic hormone (ACTH) stimulation test} [31]

This test is used to investigate adrenal steroidogenesis (Figure 2). Stimulation is induced by endovenous administration of synthetic ACTH (1-24) (Cosyntropin or Synacthen ${ }^{\circledR}$ ) at a dose of $0.25 \mathrm{mg}$ (in infants, it can be reduced to $0.125 \mathrm{mg}$ ). Adrenal enzyme deficiencies are investigated through determination of a range of hormones and precursors at baseline and at $60 \mathrm{~min}$ from stimulation [32].

\section{b-2) Chorionic gonadotropin (HCG) stimulation test [33]}

HCG that binds the LH-CG receptor of Leydig cells stimulates the production of testicular androgens. Different stimulation protocols have been developed. Determination of androgens and their precursors is performed before and at $48-72 \mathrm{~h}$ after the last injection. For diagnosis of DSD, it is important that $\mathrm{T}$, its precursors, and its DHT metabolite are measured to identify enzyme deficiencies in testicular and peripheral steroidogenesis (Figure 2).

\section{b-3) Gonadoliberin (GnRH) stimulation test}

Stimulation can be induced using the gonadotropin (LH and FSH) releasing hypothalamic factor (gonadoliberin or GnRH) (Luforan ${ }^{\circledR} 100 \mu \mathrm{g}$ i.v and $25-50 \mu \mathrm{g}$ in children), or most recently, using $\mathrm{GnRH}$ analogs (leuprorelin acetate $\left[\right.$ Procrin $\left.{ }^{\circledR}\right]$, buserelin acetate). A LH response $>5$ IU/L indicates the central activation of the hypothalamic-pituitary-gonadal axis (HPG) [34-36].

\section{c) Genetic testing}

\section{c-1) Cytogenetics and karyotype}

The karyotype is essential for DSD categorization into one of the three diagnostic groups based on the sex chromosomes found (Table 1). The gold-standard method is cytogenetics, although array-complementary genomic hybridization (array-CGH) techniques are increasingly used [21].

Apart from alterations in sex chromosomes, some DSD may involve copy number variations (CNV) (deletions, duplications, translocations), both in autosomes and sex chromosomes, which is especially relevant when the phenotype includes additional anomalies to DSD [37-40].
CNV is detected by array-CGH and can be detected by karyotype determination by array-CGH.

\section{c-2) Genetic testing}

The most frequent monogenic causes of DSD were identified in the late 20th century with the cloning of the genes codifying proteins that were known to be altered in the clinical and biochemical phenotype. This was especially useful for determination of enzyme deficiencies in adrenal and gonadal steroidogenesis (Figure 2), both in 46,XX and 46,XY DSD, and in complete androgen insensitivity. In contrast, the genes involved in the differentiation and development of male and female gonads are being progressively detected on the basis of family studies, animal models and functional studies in vitro [7, 41]. A large number of genes involved in the development of DSD encode the regulatory transcription factors of other genes (i.e., AR, DAX1, DMRT1, FOXL2, NR5A1, SOX3, SOX9, and $S R Y)$. The literature demonstrates the presence of mutations in noncoding regulatory regions, which suggests that testing noncoding DNA regions will be useful to identify the cause of some DSD in which molecular diagnosis could not be previously performed [42].

Structural analysis of a specific candidate gene is performed by automated Sanger DNA sequencing, which involves PCR amplification of coding and flanking regions and, eventually, of the promoter region. However, the introduction of high-throughput DNA sequencing allows whole exome testing (coding regions) or screening a panel of candidate genes. In addition, broad expressivity in some DSD phenotypes could be explained by an oligogenic origin, in which interaction of multiple genes could give rise to a phenotype unique to each individual [43]. The availability of these techniques in genetic testing laboratories has increased significantly as a result of improvements in their quality and cost. Thus, testing a specific gene or one of its regions will progressively be limited to the diagnosis of a new patient who is a relative of a well characterized case [21, 44-49].

\section{Biochemical and genetic markers in $46, X X$ DSD}

Table 2 contains a list of monogenic causes of DSD in the 46,XX karyotype group. The list is progressively enriched over time, especially in relation to the causes of dysgenetic gonadal development. 
Table 2: Clinical diagnoses and genes involved in disorders or differences of sex development (DSD) of monogenic etiology.

\section{DSD with 46,XX karyotype}

\begin{tabular}{|c|c|c|}
\hline Clinical diagnosis & Gene (locus) & OMIM (inheritance) (additional phenotype) \\
\hline \multicolumn{3}{|c|}{ 1. 46,XX DSD secondary to impaired gonadal development: gonadal dysgenesis, ovotesticular DSD, testicular DSD } \\
\hline Gonadal dysgenesis & BMP15 (Xp11.22) & $300510 / 300247$ (D) \\
\hline Gonadal dysgenesis & ESR2 (14q23.2-q23.3) & $618187(\mathrm{DA})$ \\
\hline Testicular DSD & FGF9 (13q12.11) & 600921 (DA:dup) (only one case reported) \\
\hline Gonadal dysgenesis & FOXL2 (3q22.3) & $\begin{array}{l}608996 \text { (DA) (Blepharophimosis, epicanthus inversus and } \\
\text { ptosis, types I and II) }\end{array}$ \\
\hline \multirow[t]{2}{*}{ Gonadal dysgenesis } & MYRF (11q12.2) & 608329 (DA) \\
\hline & & 618280 (DA) (cardiac-urogenital syndrome) \\
\hline Testicular DSD & NR2F2 (15q26.2 & $\begin{array}{l}615779 \text { (DA) (congenital heart disease, diaphragmatic hernia, } \\
\text { blepharophimosis, ptosis, and epicanthus inversus } \\
\text { syndrome) }\end{array}$ \\
\hline 1) Gonadal dysgenesis & 1) $N R 5 A 1(9 q 33.3)$ & $612964(\mathrm{DA})$ \\
\hline 2) Ovotesticular DSD & 2) NR5A1 (9q33.3) & $617480(\mathrm{DA})$ \\
\hline \multirow[t]{2}{*}{ 3) Testicular DSD } & (p.Arg92Trp) & \\
\hline & 3) NR5A1 (p.Arg92Trp) & \\
\hline Gonadal dysgenesis & NUP107 (12q15) & $\begin{array}{l}607617 \text { (RA) (reported in a consanguineous family; other } \\
\text { phenotypes with nephrotic syndrome) }\end{array}$ \\
\hline Ovotesticular DSD & RSPO1 (1p34.3) & $\begin{array}{l}610644 \text { (RA) (palmoplantar keratodermas and squamous-cell } \\
\text { skin carcinoma) }\end{array}$ \\
\hline 1) Ovotesticular DSD & SOX3 (Xq27.1) & 313430 (XL:dup) \\
\hline \multicolumn{3}{|l|}{ 2) Testicular DSD } \\
\hline Gonadal dysgenesis & SOX8 (16p13.3) & 605923 (primary ovarian insufficiency) \\
\hline 1) Ovotesticular DSD & $\operatorname{SOX9}(17 q 24.3)$ & 278850 (DA:dup) \\
\hline \multicolumn{3}{|l|}{ 2) Testicular DSD } \\
\hline 1) Ovotesticular DSD & SOX10 (22q13.1) & 609136 (DA:dup) (Waardenberg and Hirschsprung syn- \\
\hline 2) Testicular DSD & & dromes, peripheral neuropathy) \\
\hline 1) Ovotesticular DSD & SRY (Yp11.2) & $400045(\mathrm{~T})$ \\
\hline \multicolumn{3}{|l|}{ 2) Testicular DSD } \\
\hline 1) Ovotesticular DSD & WNT4 (1p36.12) & $158330(\mathrm{DA})$ \\
\hline 2) Testicular DSD & & $\begin{array}{l}611812 \text { (RA): SERKAL syndrome (sex reversal dysgenesis of } \\
\text { kidneys, adrenals, and lung), lethal biallelic }\end{array}$ \\
\hline 1) Ovotesticular DSD & WT1 (11p.13) & $\mathrm{DA}$ \\
\hline 2) Testicular DSD & & \\
\hline
\end{tabular}

\section{46,XX DSD with normal gonadal but abnormal genital development due to excess of fetal or fetoplacental androgens}

CAH due to 21-hydroxylase deficiency

CAH due to $3 \beta$-hydroxy steroid dehydrogenase

type 2 deficiency

CAH due to $11 \beta$-hydroxylase deficiency

Insensitivity to glucocorticoids

Insensitivity to estrogens

P450-oxidoreductase deficiency
CYP21A2 (6p21.33)

HSD3B2 (1p12)

CYP11B1 (8q24.3)

$G R \alpha(N R 3 C 1) 5 q 31.3$

ESR1 (6q25.1-q25.2)

$\operatorname{POR}(7 \mathrm{q} 11.23)$

CYP19A1 1 15q21.2)
201910 (RA) (adrenal deficiency)

201810 (RA) (adrenal and gonadal deficiency)

202010 (RA) (adrenal deficiency)

615962 (DA) (hypertension)

615363 (RA) (overgrowth, osteoporosis, polycystic ovary) (only one case reported)

201750 (RA)

(17 $\alpha$-hydroxylase deficiency, variable deficiencies of

21-hydroxylase and aromatase)

(Antley-Bixler syndrome, \pm craniosynostosis)

613546 (RA) (maternal and fetal virilization)

3. $46, \mathrm{XX}$ DSD with normal gonadal but abnormal Mullerian duct development

Hand-foot-genital syndrome

MURCS syndrome (Mullerian aplasia, renal apla-

sia, cervico-thoracic Somite abnormalities)
HOXA13 (7p15.2)

Multigenic:

Del 17q12
140000 (DA)

601076

$277000 / 614527 / 267400 / 192050$ 
Table 2: (continued)

\begin{tabular}{lll}
\hline DSD with 46,XX karyotype & & \\
\hline Clinical diagnosis & Gene (locus) & OMIM (inheritance) (additional phenotype) \\
\hline MRKH syndrome (Mayer-Rokitansky-Kuster- & CNV on 17q12,1q21.1, & 158330 (DA) \\
Hauser), types I and II & 22q11.21, Xq21.31 & \\
& Dupl SHOX & \\
Müllerian aplasia and hyperandrogenism & WNT4 (1p36.12) & \\
\hline
\end{tabular}

DSD, disorder or different sex development; CAH, congenital adrenal hyperplasia; D, dominant; DA, dominant autosomal; RA, recessive autosomal; XL, X-linked; T, translocation; Dup, duplication; Del, deletion; CNV, copy number variation.

\section{1) Abnormal gonadal development}

Gonadal development disorders with 46,XX karyotype include PGD and CGD, ovotesticular gonads (ovotesticular DSD) and testis development (testicular DSD) (Table 1).

The most frequent are PGD and CGD. None of these disorders is associated with genital ambiguity, and individuals have a female phenotype at birth. Clinical manifestations include delayed and/or absent puberty. Biochemical markers show elevated levels of LH and FSH, undetectable $\mathrm{AMH}$ and prepubertal estradiol (E2) concentrations. Other precursors such as androstenedione, 17- $\alpha$-hydroxyprogesterone (17OH-P), and $\mathrm{T}$ also are at prepubertal concentrations, whereas dehydroepiandrosterone (DHEA) and its sulphate increase during normal adrenarche. A milder and relatively frequent clinical form is early menopause or early ovarian failure, in which biochemistry shows an early increase in LH and FSH concentrations, reduced levels of AMH (a good marker of ovarian reserve), and low levels of E2 and progesterone (P). Evidence is progressively published on monogenic causes (Table 2), among them, inactivating mutations in BMP15, ESR2, FOXL2, MYRF, NR5A1, NUP107, and SOX8 genes. In most cases, the effect is dominant (except for NUP107) and, in some cases, they are associated with other phenotypic characteristics (Table 2).

Ovotesticular or testicular development shows genital ambiguity (even fully male external genitalia) from birth, due to fetal exposure to elevated levels of T. The biochemical profile in newborn or infant is similar to that observed in males with 46,XY karyotype. During childhood, the ability of the gonads to produce $\mathrm{T}$ can be assessed by HCG testing. During puberty, there is an increase in $\mathrm{T}$ concentrations that does not reach normal male concentrations, resulting in elevated levels of $\mathrm{LH}$ and FSH. Most monogenic causes give rise either to an ovotesticular or testicular DSD (Table 2). The first monogenic cause to be identified was the translocation of a fragment of the Y chromosome containing the $S R Y$ gene to an autosome. Some monogenic causes are associated with complex phenotypes such as mutations in NR2F2, RSPO1, SOX1O, WNT4 and, more recently, WT1; in the case of the NR5A1 gene, only the p.Arg92Trp mutation causes ovotesticular or testicular development; duplications in the FGF9, SOX3, and SOX9 genes have also been described.

\section{2) Disorders of genital development due to androgen excess}

When the gonads differentiate into ovaries and the internal genitalia are female, fetal exposure to elevated levels of androgens causes the virilization of the external genitalia. The origin of these androgens may be fetal, fetoplacental, or maternal (Table 1).

\section{a) Increased androgens of fetal origin}

Virilization of the external genitalia in most newborns with the 46,XX karyotype is induced by congenital adrenal hyperplasia (CAH). The most frequent cause is 21-hydroxylase deficiency [32, 50] (CYP21A2 gene). Its "simple virilizing” form is associated with cortisol deficiency, ACTH elevation, and the accumulation of 17OH-P, androstendione, and $\mathrm{T}$ (Figure 2). In the most severe forms, also known as "saltwasting adrenogenital syndrome", it is associated with aldosterone deficiency with concurrent hyponatremia, hyperkalemia, and increased plasma renin activity (PRA). Biochemical diagnosis is based on the finding of elevated levels of $17 \mathrm{OH}-\mathrm{P}$ (basal or post ACTH $>300 \mathrm{nmol} / \mathrm{L}$ $[>10,000 \mathrm{ng} / \mathrm{dL}])$, androstenedione, and T. Determination of glucose and electrolytes in blood and PRA is also necessary [51]. It is important to establish reference values for gestational age, since preterm newborns show significantly higher $17 \mathrm{OH}-\mathrm{P}$ concentrations, which results in high rates of false 


\section{ANDROGEN BIOSYNTHESIS PATHWAYS}

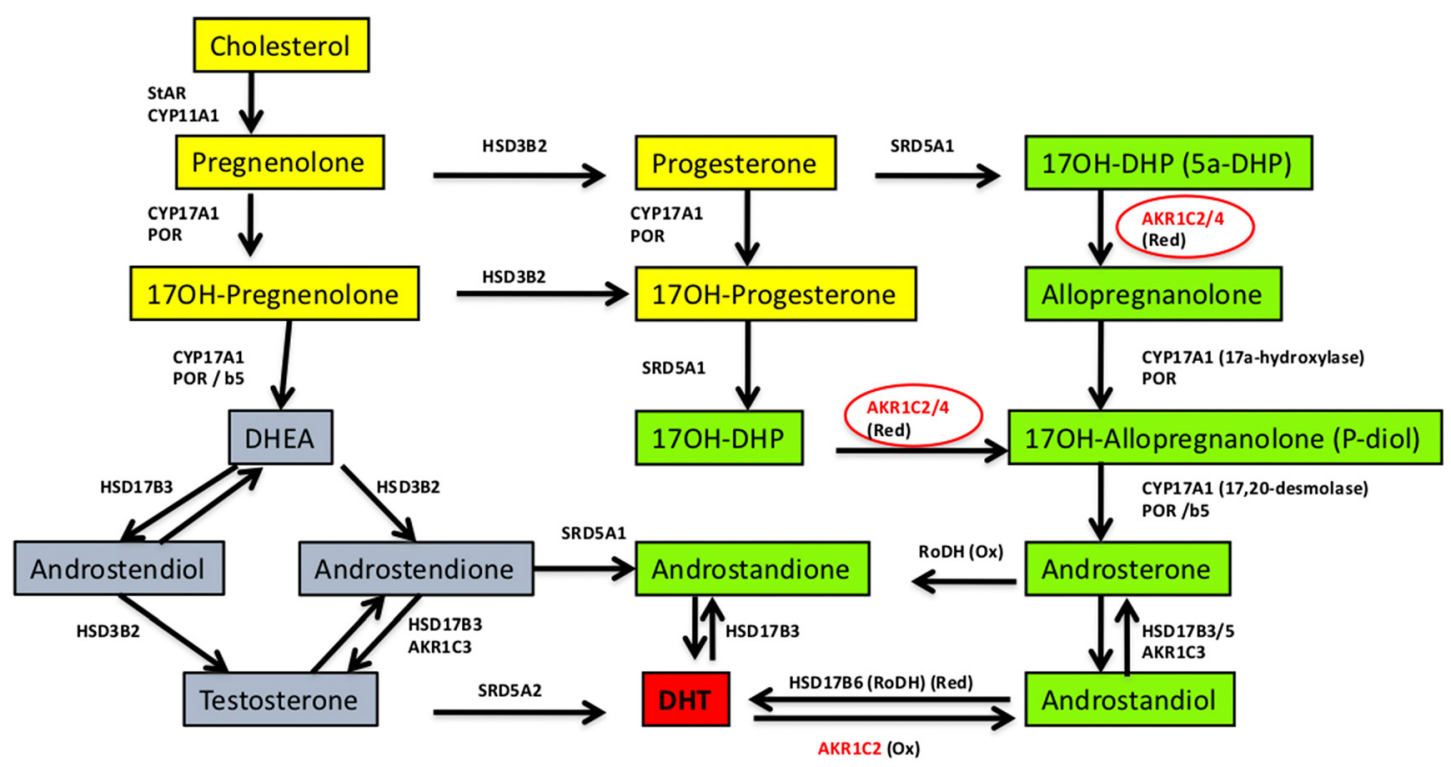

Classic pathway (frontdoor)

\section{Alternative pathway (backdoor)}

Figure 3: Androgen biosynthesis pathways: classic pathway (frontdoor) and alternative pathway (backdoor).

Classic pathway progresses from cholesterol to testosterone $(\mathrm{T})$ by mediation of the pregnenolone [StAR protein (STAR gene) and cholesterol desmolase enzyme (CYP11A1 gene)], 17-OH-pregnenolone [17alpha-hydroxylase enzyme (CYP17A1 gene) and coenzyme P450-oxidoreductase (POR gene)], dehydroepiandrosterone (DHEA) [17,20-desmolase enzyme (CYP17A1 gene), coenzyme P450-oxidoreductase (POR gene) and cytochrome $b 5$ (CYB5A gene)], androstenedione or androstenediol [enzymes 3beta-hydroxysteroid dehydrogenase type 2 (HSD3B2 gene), 17beta-hydroxysteroid dehydrogenase type 3 (HSD17B3 gene), and aldo-keto reductase family 1 member C3 (AKR1C3 gene)]. T is transformed into dihydrotestosterone (DHT) by the enzyme 5alpha-reductase type 2 (SRD5A2 gene). DHT can also be converted into androstanedione by androstenedione metabolism [enzyme 5alpha-reductase type 1(SRD5A1 gene)] and to DHT [enzyme 17 $\beta$-hydroxysteroid dehydrogenase type 3 (HSD17B3 gene)]. Alternative pathway synthesizes DHT overcoming T synthesis. Progesterone (product of pregnenolone) and $170 \mathrm{H}$-progesterone (product of progesterone) are transformed into 170H-DHP (5alpha-dihydroxy-progesterone). The latter is transformed into androstanedione or androstanediol which, in turn, are metabolized into DHT [acting several previously described enzymes as well as aldo-keto reductase family 1 members C2 y C4 (AKR1C2 y AKR1C4 genes), retinol-dehydrogenase (RODH gene), 17beta-hydroxysteroid dehydrogenase type 5 and type 6 (HSD17B5 y HSD17B6 genes)]. (Ox), oxidation; (Red), reduction.

positives [52]. Determination of 21-deoxycortisol originated from $17 \mathrm{OHP}$ conversion by 11 $\beta$-hydroxylase can be useful to minimize false positives, since it is elevated in the presence of 21-hydroxylase deficiency, but not in other adrenal deficiencies or in preterm newborns; its determination, however, is not available in many clinical laboratories [53].

Urine steroid determination by GC-MS/MS shows the activation of alternative backdoor pathway (Figure 3), concomitant to elevated levels of $5 \alpha$-pregnane-3 $\alpha, 17 \alpha$-diol20-one (P-diol), pregnanetriol (P-triol), 17OH-pregnanolone, and an elevation of the androsterone/ethiocholanolone ratio [54].

There are mild forms of this enzyme deficiency, known as "nonclassical" or "late-onset", which manifest as early pubarche, with a slight acceleration of growth velocity and bone maturation, and the appearance of pubic hair. As to the biochemical profile, there is a slight increase of basal 17OH-P with or without androstenedione and T elevation. ACTH stimulation will reveal excess $17 \mathrm{OH}-\mathrm{P}$ (31-300 nmol/L; $1,000-10,000 \mathrm{ng} / \mathrm{dL}$ ).

Molecular diagnosis will confirm the presence of mutations in the CYP21A2 gene in homozygosity or in compound heterozygosity, the effect of which is the total or almost-total inactivation of enzyme activity in the most severe forms with concomitant salt loss, as well as in the simple virilizing forms. There is an association between the genotype and the degree of virilization of patients with typical forms of the enzyme deficiency [55]. In nonclassical or late-onset forms, one of the alleles may carry a mildeffect mutation that would allow some enzymatic activity. 
Mutations in the CYP21A2 gene are the most frequent molecular disorder in humans, and its incidence varies as a function of the geographical region and social structure $[32,56]$ (Table 2).

Other less frequent causes of $\mathrm{CAH}$ are $3 \beta$-hydroxy-ste-

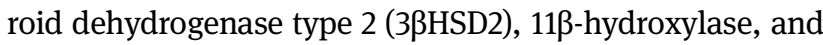
cytochrome P-450 oxidoreductase (POR) deficiencies [57].

The enzyme 3ßHSD2 (HSD3B2 gene) catalyzes two sequential reactions converting pregnenolone into $\mathrm{P}$, 17OH-pregnenolone into 17OH-P, and DHEA into androstendione (Figure 2). Patients with severe deficiency have CAH secondary to impaired cortisol and aldosterone synthesis. Patients exhibit elevated levels of steroids $\Delta 5$ (pregnenolone, 17OH-pregnenolone, DHEA) and a higher ratio of $\Delta 5$ to $\Delta 4$ steroids (P, $17 \mathrm{OH}-\mathrm{P}$ and androstendione). However, $170 \mathrm{H}-\mathrm{P}$ concentrations may be elevated as a result of peripheral conversion of $\Delta 5-17 \mathrm{OH}$-pregnenolone by the 33HSD type 1 enzyme. Biochemical diagnosis is based on the finding of elevated concentrations of $17 \mathrm{OH}$-pregnenolone $(>150 \mathrm{nmol} / \mathrm{L})$ at baseline or after ACTH stimulation [58]. Molecular diagnosis will confirm the presence of $H S D 3 B 2$ inactivating mutations in homozygosis or compound heterozygosis (Table 2).

The enzyme 11ß-hydroxylase converts 11-deoxicortisol into cortisol and 11-deoxycorticosterone into corticosterone (Figure 2). 11ß-hydroxylase deficiency induces $\mathrm{CAH}$ with concurrent cortisol and aldosterone deficiency resulting in androgen synthesis (T), and it is associated with a very significant virilization of the female fetus. The hormone profile is characterized by diminished levels of cortisol and aldosterone, with increased ACTH concentrations but inhibited PRA. The most robust diagnostic marker is elevated levels of 11-deoxicortisol and 11-deoxicorticosterone, although determination of these parameters is not available in many clinical laboratories. Up to $60 \%$ of patients have hypertension secondary to 11-deoxicorticosterone accumulation, which has mineralocorticoid activity. The steroid profile in urine shows reduced levels of cortisol and increased levels of 11-deoxicorticosterone metabolites [59].

There are mild forms of the enzyme deficiency [60]. Molecular diagnosis will confirm the presence of mutations in the CYP11B1 gene in homozygosis or compound heterozygosis (Table 2).

Resistance to glucocorticoids is a very rare cause of virilization of a female fetus. A mutation of the glucocorticoid receptor gene (GR $\alpha$ or NR3C1) (Table 2) causes cortisol and ACTH hypersecretion, without clinical evidence of hypercortisolism but with manifestations of androgen and mineralocorticoid excess [61].

Estrogen resistance induced by inactivating mutations in the E2 receptor alpha (ESR1 gene) (Table 2) is a very rare condition that was first described in males; in females, the morphology of external genitalia at birth has not yet been described in detail, but patients develop postnatal virilization by the development of a polycystic ovary with increased levels of androstenedione and $\mathrm{T}$, as well as tall stature and osteoporosis [62].

\section{b) Increased fetoplacental androgen production}

P450-oxidoreductase (POR) is a flavoprotein bound to the membrane of cytochrome $c$ that plays a crucial role in electron transfer from NADPH to microsomal enzymes P450 (CYP21, CYP17, and CYP19 or aromatase). POR deficiency is characterized by a partial, varying impairment of different enzyme activities (Figure 2): 17 $\alpha$-hydroxylase and 17,20-lyase, associated or not with 21-hydroxylase and aromatase. Patients exhibit a broad phenotypical spectrum and may present characteristic skeletal malformations (Antley-Bixler syndrome). It may cause $\mathrm{CAH}$ and genital ambiguity [63]. As to biochemistry, patients may have normal or low levels of cortisol, high levels of 17OH-P and $\mathrm{T}$, and abnormal concentrations of some steroids (and their metabolites) of the backdoor pathway (Figure 3). The steroid profile in urine shows accumulation of pregnenolone and $\mathrm{P}$ metabolites. Female neonates have ambiguous genitalia due to fetal exposure to excess androgens secondary to aromatase (CYP19) deficiency and/or DHT synthesis through the backdoor pathway [64]. The mother may show signs of virilization during pregnancy, with elevated $\mathrm{T}$ concentrations. Virilization of the female neonate does not progress, and circulating androgen concentrations remain normal until puberty, when ovarian E2 synthesis decreases and the production of backdoor pathway steroidogenesis precursors increases [65]. Molecular diagnosis will confirm the presence of POR-inactivating mutations in homozygosis or compound heterozygosis (Table 2).

The enzyme aromatase (CYP19) catalyzes T conversion into E2 and DHEA conversion into estrone (E1). In the absence of aromatase activity, the placenta cannot convert DHEA sulphate, produced in large amounts by the fetal adrenal gland, into estrogens (E1, E2, and estriol) and transforms it into T, which causes virilization of the 46,XX fetus and the mother [66]. Patients generally show elevated levels of $\mathrm{T}$ and gonadotropins, especially FSH. Molecular diagnosis will confirm the presence of mutations in the CYP19A1 gene in homozygosis or compound heterozygosis (Table 2).

Androgen-producing fetal or placental tumors: cases have been reported of congenital adrenal tumors causing the virilization of a $46, \mathrm{XX}$ fetus. 


\section{c) Elevation of maternal androgen production}

Excess androgens may be transferred from the mother to the 46,XX fetus, either by secretion from virilizing tumors during pregnancy (including pregnancy luteoma and Krukenberg tumor), by pharmacological therapies or by environmental pollutants with androgenic effects, or by poor therapeutic monitoring during pregnancy of a mother with CAH (Table 1).

\section{3) Internal genitalia development disorder}

Some individuals may exhibit isolated malformations of female internal genital ducts (uterus, vagina, and fallopian tubes). These malformations may be caused by incomplete development or the presence of abnormal structures (Table 1). They are not frequent and, in some cases, there may be a family history of malformations, which suggests a genetic origin, although the etiology is rarely elucidated.

There are no specific biochemical markers. Only amenorrhea, dysmenorrhea, and infertility may give some diagnostic guidance. Malformations include aplasia or hypoplasia of the uterus and the fallopian tubes, a bicornuate or bipartite uterus that may be associated with malformations in other systems or tissues, such as the hand-foot-genital syndrome (associated with the HOXA13 gene); MURCS syndrome (Mullerian aplasia, renal aplasia, cervico-thoracic somite abnormalities, currently defined as multigenic); and the MRKH (Mayer-Rokitansky-Kuster-Hauser) syndrome types I and II, where several genetic disorders have been described; and finally WNT4-inactivating mutations, which have been associated with ovotesticular or testicular development with potential Mullerian duct aplasia (Table 2).

Research funding: None declared.

Author contributions: All authors have accepted responsibility for the entire content of this manuscript and approved its submission.

Competing interests: Authors state no conflict of interest. Informed consent: Not applicable.

Ethical approval: The local Institutional Review Board deemed the study exempt from review.

\section{References}

1. Eggers S, Sinclair A. Mammalian sex determination-insights from humans and mice. Chromosome Res 2012;20:215-38.

2. Munger SC, Natarajan A, Looger LL, Ohler U, Capel B. Fine time course expression analysis identifies cascades of activation and repression and maps a putative regulator of mammalian sex determination. PLoS Genet 2013;9:e1003630.

3. Eggers S, Ohnesorg T, Sinclair A. Genetic regulation of mammalian gonad development. Nat Rev Endocrinol 2014;10:673-83.

4. Berta P, Hawkins J, Sinclair A, Taylor A, Griffiths BL, Goodfellow $\mathrm{PN}$, et al. Genetic evidence equating SRY and the testisdetermining factor. Nature 1990;348:448-50.

5. Harley VR, Clarkson MJ, Argentaro A. The molecular action and regulation of the testis-determining factors, SRY (sexdetermining region on the Y chromosome) and SOX9 [SRY-related high-mobility group (HMG) box 9]. Endocr Rev 2003;24:466-87.

6. Sekido R, Lovell-Badge R. Sex determination and SRY: down to a wink and a nudge? Trends Genet 2009;25:19-29.

7. Bashamboo A, Eozenou C, Rojo S, McElreavey K. Anomalies in human sex determination provide unique insights into the complex genetic interactions of early gonad development. Clin Genet 2017;91:143-56.

8. Zhao F, Yao HH. A tale of two tracts: history, current advances, and future directions of research on sexual differentiation of reproductive tracts. Biol Reprod 2019;101:602-16.

9. Imperato-McGinley J, Zhu YS. Androgens and male physiology the syndrome of 5alpha-reductase-2 deficiency. Mol Cell Endocrinol 2002;198:51-9.

10. Yang JH, Menshenina J, Cunha GR, Place N, Baskin LS. Morphology of mouse external genitalia: implications for a role of estrogen in sexual dimorphism of the mouse genital tubercle. J Urol 2010;184(4 Suppl):1604-9.

11. Lee PA, Nordenström A, Houk CP, Ahmed SF, Auchus R, Baratz A, et al. Global DSD update consortium. Global disorders of sex development update since 2006: perceptions, approach and care. Horm Res Paediatr 2016;85:158-80.

12. Ahmed SF, Bashamboo A, Lucas-Herald A, McElreavey K. Understanding the genetic aetiology in patients with XY DSD. $\mathrm{Br}$ Med Bull 2013;106:67-89.

13. Ahmed SF, Achermann JC, Arlt W, Balen A, Conway G, Edwards Z, et al. Society for Endocrinology UK guidance on the initial evaluation of an infant or an adolescent with a suspected disorder of sex development. Clin Endocrinol 2016;84:771-88.

14. Baetens D, Mladenov W, Delle Chiaie B, Menten B, Desloovere A, lotova $\mathrm{V}$, et al. Extensive clinical, hormonal and genetic screening in a large consecutive series of $46, \mathrm{XY}$ neonates and infants with atypical sexual development. Orphanet J Rare Dis 2014;9:209.

15. Bangalore Krishna K, Houk CP, Lee PA. Pragmatic approach to intersex, including genital ambiguity, in the newborn. Semin Perinatol 2017;41:244-51.

16. León NY, Reyes AP, Harley VR. A clinical algorithm to diagnose differences of sex development. Lancet Diabetes Endocrinol 2019;7:560-74.

17. Kyriakou A, Lucas-Herald AK, McGowan R, Tobias ES, Ahmed SF. Disorders of sex development: advances in genetic diagnosis and challenges in management. Adv Genom Genet 2015;5:165-77.

18. Yatsenko SA, Witchel SF. Genetic approach to ambiguous genitalia and disorders of sex development: what clinicians need to know. Semin Perinatol 2017;41:232-43.

19. Nixon R, Cerqueira V, Kyriakou A, Lucas-Herald A, McNeilly J, McMillan M, et al. Prevalence of endocrine and genetic abnormalities in boys evaluated systematically for a disorder of sex development. Hum Reprod 2017;32:2130-7.

20. Kolesinska Z, Acierno J Jr, Ahmed SF, Xu C, Kapczuk K, SkorczykWerner A, et al. Integrating clinical and genetic approaches in the 
diagnosis of 46,XY disorders of sex development. Endocr Connect 2018;7:1480-90.

21. Audi L, Ahmed SF, Krone N, Cools M, McElreavey K, Holterhus PM, et al. GENETICS IN ENDOCRINOLOGY: approaches to molecular genetic diagnosis in the management of differences/disorders of sex development (DSD): position paper of EU COST Action BM 1303 'DSDnet'. Eur J Endocrinol 2018;179:R197-206.

22. Yarrow JF, Beck DT, Conover CF, Beggs LA, Goldberger BA, Borst $\mathrm{SE}$. Invalidation of a commercially available human $5 \alpha$-dihydrotestosterone immunoassay. Steroids 2013;78: 1220-5.

23. Wudy SA, Hartmann M, Solleder C, Homoki J. Determination of 17alpha-hydroxypregnenolone in human plasma by routine isotope dilution mass spectrometry using benchtop gas chromatography-mass selective detection. Steroids 2001;66: 759-62.

24. Kulle A, Krone N, Holterhus PM, Schuler G, Greaves RF, Juul A, et al. Steroid hormone analysis in diagnosis and treatment of DSD: position paper of EU COST Action BM 1303 'DSDnet'. Eur J Endocrinol 2017;176:P1-9.

25. Hannema SE, de Rijke YB. Improving laboratory assessment in disorders of sex development through a multidisciplinary network. Sex Dev 2018;12:135-9.

26. Honour JW, Conway E, Hodkinson R, Lam F. The evolution of methods for urinary steroid metabolomics in clinical investigations particularly in childhood. J Steroid Biochem Mol Biol 2018;181:28-51.

27. Sikaris K, McLachlan RI, Kazlauskas R, de Kretser D, Holden CA, Handelsman DJ. Reproductive hormone reference intervals for healthy fertile young men: evaluation of automated platform assays. J Clin Endocrinol Metab 2005;90:5928-36.

28. Gassner D, Jung R. First fully automated immunoassay for antiMüllerian hormone. Clin Chem Lab Med 2014;52:1143-52.

29. Johannsen TH, Main KM, Ljubicic ML, Jensen T, Andersen HR, Andersen MS, et al. Sex differences in reproductive hormones during mini-puberty in infants with normal and disordered sex development. J Clin Endocrinol Metab 2018;103:3028-37.

30. Johannsen TH, Andersson AM, Ahmed SF, de Rijke YB, Greaves RF, Hartmann MF, et al. Peptide hormone analysis in diagnosis and treatment of Differences of Sex Development: joint position paper of EU COST action 'DSDnet' and European Reference Network on Rare Endocrine Conditions. Eur J Endocrinol 2020;182:P1-15.

31. Auchus RJ, Chang AY. 46,XX DSD: the masculinised female. Best Pract Res Clin Endocrinol Metabol 2010;24:219-42.

32. Nimkarn S, Gangishetti PK, Yau M, New MI. 21-HydroxylaseDeficient congenital adrenal hyperplasia. In: Adam MP, Ardinger HH, Pagon RA, Wallace SE, Bean LJH, Stephens K, Amemiya A, editors. GeneReviews ${ }^{\circledR}$ [Internet]. Seattle, WA: University of Washington; 2002.

33. Bertelloni S, Russo G, Baroncelli GI. Human chorionic gonadotropin test: old uncertainties, new perspectives, and value in $46, \mathrm{XY}$ disorders of sex development. Sex Dev 2018;12:41-9.

34. Vestergaard ET, Schjørring ME, Kamperis K, Petersen KK, Rittig S, Juul A, et al. The follicle-stimulating hormone (FSH) and luteinizing hormone $(\mathrm{LH})$ response to a gonadotropin-releasing hormone analogue test in healthy prepubertal girls aged 10 months to 6 years. Eur J Endocrinol 2017;176:747-53.

35. Carretto F, Salinas-Vert I, Granada-Yvern ML, Murillo-Vallés M, Gómez-Gómez C, Puig-Domingo M, et al. The usefulness of the leuprolide stimulation test as a diagnostic method of idiopathic central precocious puberty in girls. Horm Metab Res 2014;46: 959-63.

36. Bangalore Krishna K, Fuqua JS, Rogol AD, Klein KO, Popovic J, Houk CP, et al. Use of gonadotropin-releasing hormone analogs in children: update by an international consortium. Horm Res Paediatr 2019;91:357-72.

37. Ledig S, Hiort O, Scherer G, Hoffmann M, Wolff G, Morlot S, et al. Array-CGH analysis in patients with syndromic and nonsyndromic $X Y$ gonadal dysgenesis: evaluation of array $\mathrm{CGH}$ as diagnostic tool and search for new candidate loci. Hum Reprod 2010;25:2637-46.

38. White S, Ohnesorg T, Notini A, Roeszler K, Hewitt J, Daggag H, et al. Copy number variation in patients with disorders of sex development due to 46,XY gonadal dysgenesis. PloS One 2011;6: e17793.

39. Kon M, Fukami M. Submicroscopic copy-number variations associated with 46,XY disorders of sex development. Mol Cell Pediatr 2015;2:7.

40. Croft B, Ohnesorg T, Sinclair AH. The role of copy number variants in disorders of sex development. Sex Dev 2018;12:19-29.

41. Bashamboo A, McElreavey K. Human sex-determination and disorders of sex-development (DSD). Semin Cell Dev Biol 2015; 45:77-83.

42. Baetens D, Mendonça BB, Verdin H, Cools M, De Baere E. Noncoding variation in disorders of sex development. Clin Genet 2017;91:163-72.

43. Camats N, Flück CE, Audí L. Oligogenic origin of differences of sex development in humans. Int J Mol Sci 2020:21: E1809.

44. Baxter RM, Arboleda VA, Lee H, Barseghyan H, Adam MP, Fechner PY, et al. Exome sequencing for the diagnosis of 46,XY disorders of sex development. J Clin Endocrinol Metab 2015;100:E333-44.

45. Dong Y, Yi Y, Yao H, Yang Z, Hu H, Liu J, et al. Targeted nextgeneration sequencing identification of mutations in patients with disorders of sex development. BMC Med Genet 20162016;17:23.

46. Alhomaidah D, McGowan R, Ahmed SF. The current state of diagnostic genetics for conditions affecting sex development. Clin Genet 2017;91:157-62.

47. Wang H, Zhang L, Wang N, Zhu H, Han B, Sun F, et al. Nextgeneration sequencing reveals genetic landscape in $46, X Y$ disorders of sexual development patients with variable phenotypes. Hum Genet 2018;137:265-77.

48. Hughes LA, McKay-Bounford K, Webb EA, Dasani P, Clokie S, Chandran $\mathrm{H}$, et al. Next generation sequencing (NGS) to improve the diagnosis and management of patients with disorders of sex development (DSD). Endocr Connect 2019;8:100-10.

49. Jacobson JD, Willig LK, Gatti J, Strickland J, Egan A, Saunders C, et al. High molecular diagnosis rate in undermasculinized males with differences in sex development using a stepwise approach. Endocrinology 2020;161:bqz015.

50. Speiser PW, Arlt W, Auchus RJ, Baskin LS, Conway GS, Merke DP, et al. Congenital adrenal hyperplasia due to steroid 21-hydroxylase deficiency: an endocrine society clinical practice guideline. J Clin Endocrinol Metab 2018;103:4043-88.

51. Honour JW. 17-Hydroxyprogesterone in children, adolescents and adults. Ann Clin Biochem 2014;51:424-40.

52. Van der Kamp H, Oudshoorn C, Elvers B, van Baarle M, Otten B, Wit J, et al. Cuttoff levels of 17-alfa hydroxyprogesterone in neonatal screening for congenital adrenal hyperplasia should be based on gestational age rather than on birth weight. J Clin Endocrinol Metab 2005;90:3904-7. 
53. Miller WL. Congenital adrenal hyperplasia: time to replace $170 \mathrm{HP}$ with 21-deoxycortisol. Horm Res Paediatr 2019;91:416-20.

54. Kamrath C, Hochberg Z, Hartmann MF, Remer T, Wudy SA. Increased activation of the alternative 'backdoor' pathway in patients with 21-hydroxylase deficiency: evidence from urinary steroid hormone analysis. J Clin Endocrinol Metab 2012;97:E367-75.

55. Neocleous V, Fanis P, Phylactou LA, Skordis N. Genotype is associated to the degree of virilization in patients with classic congenital adrenal hyperplasia. Front Endocrinol 2018;9:733.

56. Parsa AA, New MI. Steroid 21-hydroxylase deficiency in congenital adrenal hyperplasia. J Steroid Biochem Mol Biol 2017; 165:2-11.

57. Baronio F, Ortolano R, Menabò S, Cassio A, Baldazzi L, Di Natale $\mathrm{V}$, et al. 46,XX DSD due to androgen excess in monogenic disorders of steroidogenesis: genetic, biochemical, and clinical features. Int J Mol Sci 2019;20:E4605.

58. Lutfallah C, Wang W, Mason JL, Chang YT, Haider A, Rich B, et al. Newly proposed hormonal criteria via genotypic proof for type II 3beta-hydroxysteroid dehydrogenase deficiency. J Clin Endocrinol Metab 2002;87:2611-22.

59. Khattab A, Haider S, Kumar A, Dhawan S, Alam D, Romero R, et al. Clinical, genetic, and structural basis of congenital adrenal hyperplasia due to $11 \beta$-hydroxylase deficiency. Proc Natl Acad Sci U S A 2017;114: E1933-40.

60. Parajes S, Loidi L, Reisch N, Dhir V, Rose IT, Hampel R, et al. Functional consequences of seven novel mutations in the CYP11B1 gene: four mutations associated with nonclassic and three mutations causing classic 11 beta\}-hydroxylase deficiency. J Clin Endocrinol Metab 2010;95:779-88.
61. Mendonca BB, Leite MV, de Castro M, Kino T, Elias LL, Bachega TA, et al. Female pseudohermaphroditism caused by a novel homozygous missense mutation of the GR gene. J Clin Endocrinol Metab 2002;87:1805-9.

62. Quaynor SD, Stradtman EW Jr, Kim HG, Shen Y, Chorich LP, Schreihofer DA, et al. Delayed puberty and estrogen resistance in a woman with estrogen receptor $\alpha$ variant. N Engl J Med 2013;369: 164-71.

63. Burkhard FZ, Parween S, Udhane SS, Flück CE, Pandey AV. P450 0xidoreductase deficiency: analysis of mutations and polymorphisms. J Steroid Biochem Mol Biol 2017;165: 38-50.

64. Reisch N, Taylor AE, Nogueira EF, Asby DJ, Dhir V, Berry A, et al. Alternative pathway androgen biosynthesis and human fetal female virilization. Proc Natl Acad Sci U S A 2019;116: 22294-9.

65. Parween S, Fernández-Cancio M, Benito-Sanz S, Camats N, Rojas Velazquez MN, López-Siguero JP, et al. Molecular basis of CYP19A1 deficiency in a 46,XX patient with R550W mutation in POR: expanding the PORD phenotype. J Clin Endocrinol Metab 2020;105:dgaa076.

66. Lin L, Ercan O, Raza J, Burren CP, Creighton SM, Auchus RJ, et al. Variable phenotypes associated with aromatase (CYP19) insufficiency in humans. J Clin Endocrinol Metab 2007;92: 982-90.

Article Note: The original article can be found here: https://doi.org/ 10.1515/almed-2020-0119. 